\title{
The Comparison of Lower and Higher Extremity Anaerobic Power Capacities of Indoor Athletes
}

\author{
Aydin Senturk ${ }^{1}$ \\ ${ }^{1}$ Dumlupınar University, Physical Education and Sport, Department of Coaching Education, Kütahya, Turkey \\ Corresponding: Aydin Senturk, Dumlupınar University, Physical Education and Sport, Department of Coaching \\ Education, Kütahya, Turkey. E-mail: asenturk55@yahoo.com
}

Received: July 3, 2019

Accepted: August 15, 2019 Online Published: September 20, 2019

doi:10.5539/jel.v8n5p100

URL: https://doi.org/10.5539/jel.v8n5p100

\begin{abstract}
The objective of this study is the comparison of lower and higher extremity anaerobic power capacities of indoor athletes. 25 handball players (13 females, 12 males), 22 basketball players (10 females, 12 males) and experimental control group (10 females, 13 males, total 23), it means 70 athletes from amateur leagues participated in the research. Lower extremity anaerobic powers of participants were measured by wattbike pro power bike. Higher extremity anaerobic powers of participants were measured by myotest.

Data statistics were done by Windows SPSS 22.0. For dispersion of averages and standart deviations, descriptive statistics methods were used. In order to see the effects of gender and branch variances of participants on lower and higher extremity, Two-Way Manova analysis was used. Moreover, in order to see differences clearly, Screen Plot graphics were performed. In higher extremity measurements analysis, for 3 higher extremity values except velocity, male participants had higher averages than female participants do $(p<0.05)$. Based on Pairwise Comparisons results for branches, both Power Wkg and Power Max W kg values, handball participants had significant higher averages than control group participants did $(p<0.05)$. For lower extremity variances, female participants had lower averages than male participants. For Powermass values, handball players had higher averages than control group did. For Powerpeak and Power Average variances, control group participants had significant lower averages than both basketball players and handball players did $(\mathrm{p}<0.05)$. For all values, there were no significant differences between handball and basketball players, except male height measurements $(\mathrm{p}>$ $0.05)$.
\end{abstract}

Keywords: anaerobic power, indoor athletes, sport

\section{Introduction}

Training is not a new discovery. It is known that people were trained for olympic and military purposes in Egypt and Greece. Like old days, today, a person can prepare himself for a certain purpose by training (Bompa, 2007). Recently, physical and motor capacities of male and female indoor athletes were examined (Pantelis et al., 2014). For example; basketball (Ziv \& Lidor, 2009), handball (Lidor \& Ziv, 2011) and volleyball (Lidor \& Ziv, 2010). The purpose of all those studies is to prepare proper training programmes and to find the ways to maximize performance (Pantelis et al., 2014). To increase intramuscular ATP-CP energy capacity, anaerobic load is required, which is repetitive, powerfull and short term (McArdle et al., 1996).

It is important that studies should be performed for several branches. Anaerobic capacity is used predominantly in basketball and handball (Jelena et al., 2009). One of the most used tests to measure anaerobic adequacy is Wingate bike ergometer (Abbasi \& Mosayeb, 2012), such as Wattbike bike ergometer. Anaerobic activity is energy spending using anaerobic metabolysm (Wilmore \& Costill, 2004). It lasts less than 90 seconds with a big effort (without oxsygen). Second system anaerobic is glycolysis and it may continue. Anaerobic metabolysm is used extensively during sports games (Michael et al., 2009).

At the end of endurance trainings, less lactic acid is produced at the same submaximal work load. In order to be successfull, athletes should have maximal aerobic power, at the same time they should have the ability to use this power with the least lactic acid accumulation. This ensures that athletes may show higher performance without exhaustion early in the match (Holloszy \& Coyle, 1984; Wilmore \& Costil, 2004). 


\section{Methods}

Total 70 athletes were participated in the study, 25 handball players (13 females, 12 males), 22 basketball players (10 females, 12 males) and 25 people for the control group (10 females, 13 males). Participants were informed about the test one day before the measurement. They knew that those tests are healthy and they were volunteers, confirming acceptance with a signed form. One requirement was that participants should be healthy athletes. Between tests, participants rested fully. Height: Holtain Limited height measurement tool was utilized. Participants, standing upright, naked feet, minimum clothes, were measured by calliper. Body Weight: Body weight was measured by Angel electronic scale (precision $0.01 \mathrm{~kg}$ ).

Anaerobic Power: Wattbike pro anaerobic power bike is used for that test, 30 seconds with maximum speed. Before test, bike is tuned $60-70 \mathrm{~W}$ work load, $60-70$ speed /minute pedal speed with a 5 minutes warm up. After warming up, 5 minutes passive relaxation. Later, saddle and handlebar were adjusted for each participant and feet were fastened to the saddle by clips.

The test protocol will be told to subjects and they ensured to be ready for the test. Sufficient water intake and sleep patterns will be provided before the test. All apparatus will be passed through the required calibration before the test. Myotest tool will be mounted to the inside of the olympic bar, outside of the holding areas, with three centimeters away from the shoulder on bench press. The exercise adjustments will also be connected to a computer-based interface with the Ballistic Measurement System (BMS). The measurement speed will taken as $200 \mathrm{HZ}$ (20). Myotest and BMS will collect the data of repeated movements. It will be awaited, for Mayotest make in an axis movement and the bar fixed for each set to collect data. Collection of the data will start before the movement and subjects will wait for a second after Myotest,. After each break given after the movement, the subjects will be kept waiting for a second more. Meanwhile, data collection will be paused. Then the subjects will be asked to perform the movement. Myotest will be kept in a vertical position during the whole data collection process. The highest force and strain will be observed in the concentric part of the movement for each movement.

For each participant, before first test, air resistance unit and magnetic resistance settings are applied for body weights, and then in 5 seconds with a visual warning the test starts. Volunteer participants pedal 30 seconds with maximum speed. Participants were motivated verbally during the test. Information concerning power parameters during tests were transferred to programme with 30'power software. All power parameters were calculated by software programme.

\subsection{Statistical Analysis}

For means and standart deviations, descriptive statistics methods were utilized. In order to see the effects of gender and branch variances of participants on lower and higher extremity, Two-Way Manova analysis was used. Moreover, in order to see differences clearly, Screen Plot graphics were performed.

\section{Findings}

In analysis concerning hypothesis; Levene Test showed that variance homogeneity was provided in lower dimensions of epistemologic concepts. Simple correlation analysis done among dependent variables showed that there is a linear relationship between each binary combination of dependent variables and correlation coefficients are 0.7 at the highest (Pallant, 2001). Box Test value is greater than 0.05 (BoxM $=0.21)$ (Pallant, 2001). It shows that variance-covariance matrices of the points belonging to dependent variables are homogeneous. In that case, we may think that variances of groups are equal for each of the dependent variables and covariances are equal for all possible binary combinations of dependent variables (Büyüköztürk, 2002).

Table 1 . The effect of gender and branch of participants on high extremity values

\begin{tabular}{lllllll}
\hline Multiple Comparions & Value & $\mathrm{F}$ & $\mathrm{Sd}$ & Error df & $\mathrm{p}$ & $\eta 2$ \\
\hline Intercept & 0.009 & 1654.80 & 4 & 60 & 0.00 & $0.99^{*}$ \\
Gender & 0.184 & 67.464 & 4 & 61 & 0.02 & $0.81^{*}$ \\
Branch & 0.728 & 2.629 & 8 & 122 & 0.01 & $0.42^{*}$ \\
Gender*Branch & 0.831 & 5.265 & 8 & 122 & 0.17 & 0.08 \\
\hline
\end{tabular}

According to Two-Way MANOVA results; gender variable has a significant effect on high extremity values of participants. $\left(\lambda=0.184, \mathrm{~F}_{(4)}=67.464, \mathrm{p}<.05\right)$. Besides, branch variable has the same effect on those values. $(\lambda=$ $\left.0.728, \mathrm{~F}_{(8)}=2.629, \mathrm{p}<.05\right)$. When Wilk's lambda test results' partial eta squared effect values are examined, 
gender has high effect on high extremity $(\eta 2=0.81)$; branch variable has medium effect on high extremity $(\eta 2=$ $0.42)$. There is no joint effect of these two variables on high extremity $(p>0.05)$. Analysis of high extremity measurements show that male participants have higher averages than females do, on three high extremity values, except velocity $(\mathrm{p}<0.05)$. According to Pairwise Comparisons results on branch based, for both Power Wkg and Power Max W kg values, handball participants have significantly higher averages than control group participants do $(\mathrm{p}<0.05)$.
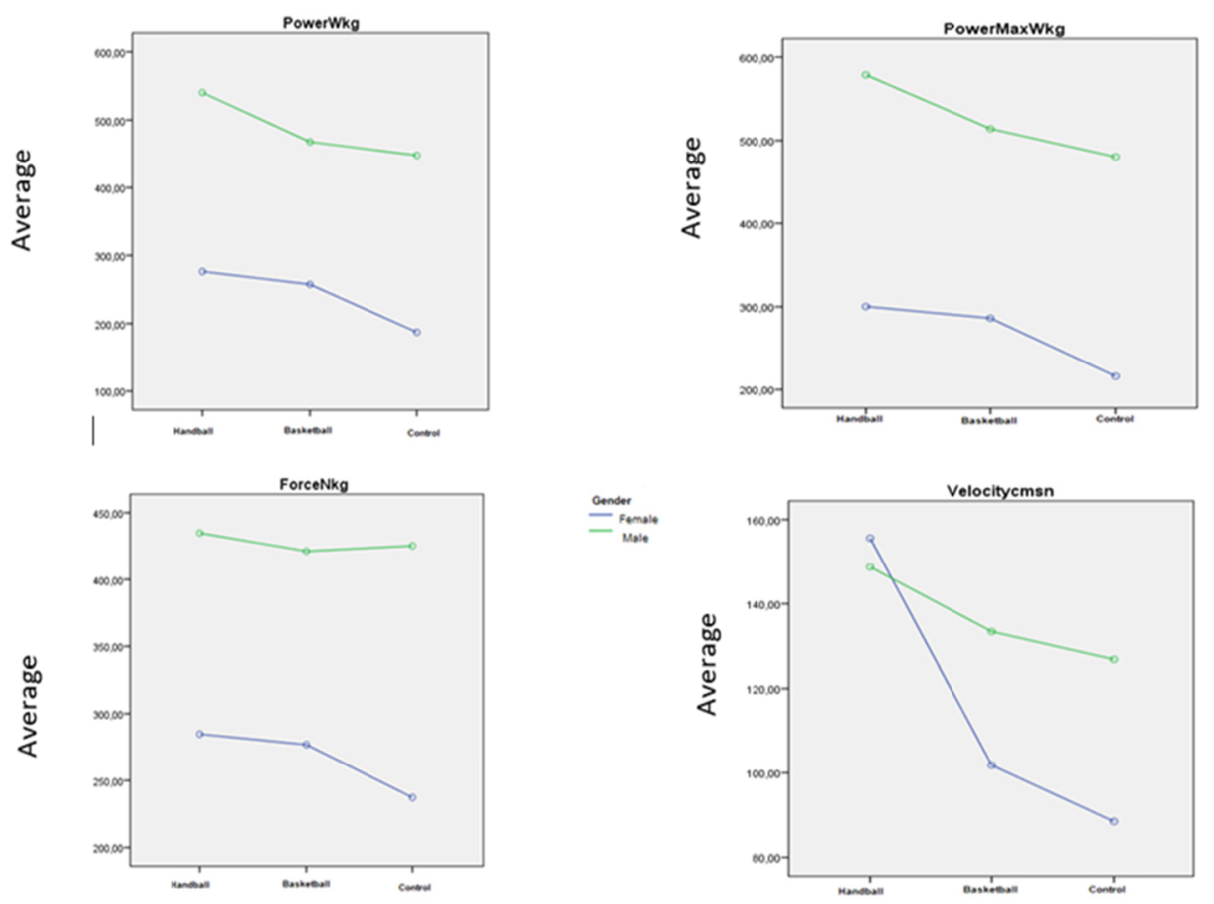

Figure 1. Comparison of Gender* Sports (PowerWkg, PowerMaxWkg, Force Nkg, Velocitycmsn)

Above graphics supports MANOVA test. Female participants have lower averages than males do, for three variables, except Velocity. Besides, for both Power Wkg and Power Max W kg values, handball participants have significantly higher averages than control group participants do.

Table 2. The effect of gender and branch of participants on low extremity values

\begin{tabular}{lllllll}
\hline Multiple Comparions & Value & $\mathrm{F}$ & $\mathrm{sd}$ & Error df & $\mathrm{p}$ & $\eta 2$ \\
\hline Intercept & 0.013 & 1516.43 & 3 & 62 & 0.00 & $0.98^{*}$ \\
Gender & 0.318 & 44.397 & 3 & 62 & 0.00 & $0.70^{*}$ \\
Branch & 0.649 & 4.996 & 6 & 124 & 0.00 & $0.20^{*}$ \\
Gender*Branch & 0.762 & 3.002 & 6 & 124 & 0.09 & $0.12^{*}$ \\
\hline
\end{tabular}

According to Two-Way MANOVA results; gender variable has a significant effect on lower extremity values of participants $\left(\lambda=0.318, \mathrm{~F}_{(3)}=44.397, \mathrm{p}<.05\right)$. Besides, branch variable has a significant effect on lower extremity values of the participants $\left(\lambda=0.649, \mathrm{~F}_{(6)}=4.996, \mathrm{p}<.05\right)$. When Wilk's lambda test results' partial eta squared effect values are examined, gender has high effect on high extremity $(\eta 2=0.70)$; branch variable has a low effect on it $(\eta 2=0.20)$. Moreover; gender and branch variables have joint effect on lower extremities of the participants $\left(\lambda=0.762, \mathrm{~F}_{(6)}=3.002, \mathrm{p}<.05\right)$. On lower extremity measurements, males have higher averages than females do, like higher extremity values $(\mathrm{p}<0.05)$. According to Pairwise Comparisons results on branch based, for Powermass value, handball players have significantly higher averages than control group players do; for Powerpeak and Power Average variables, control group participants have significantly lower averages than both basketball and handball players $(\mathrm{p}<0.05)$. 

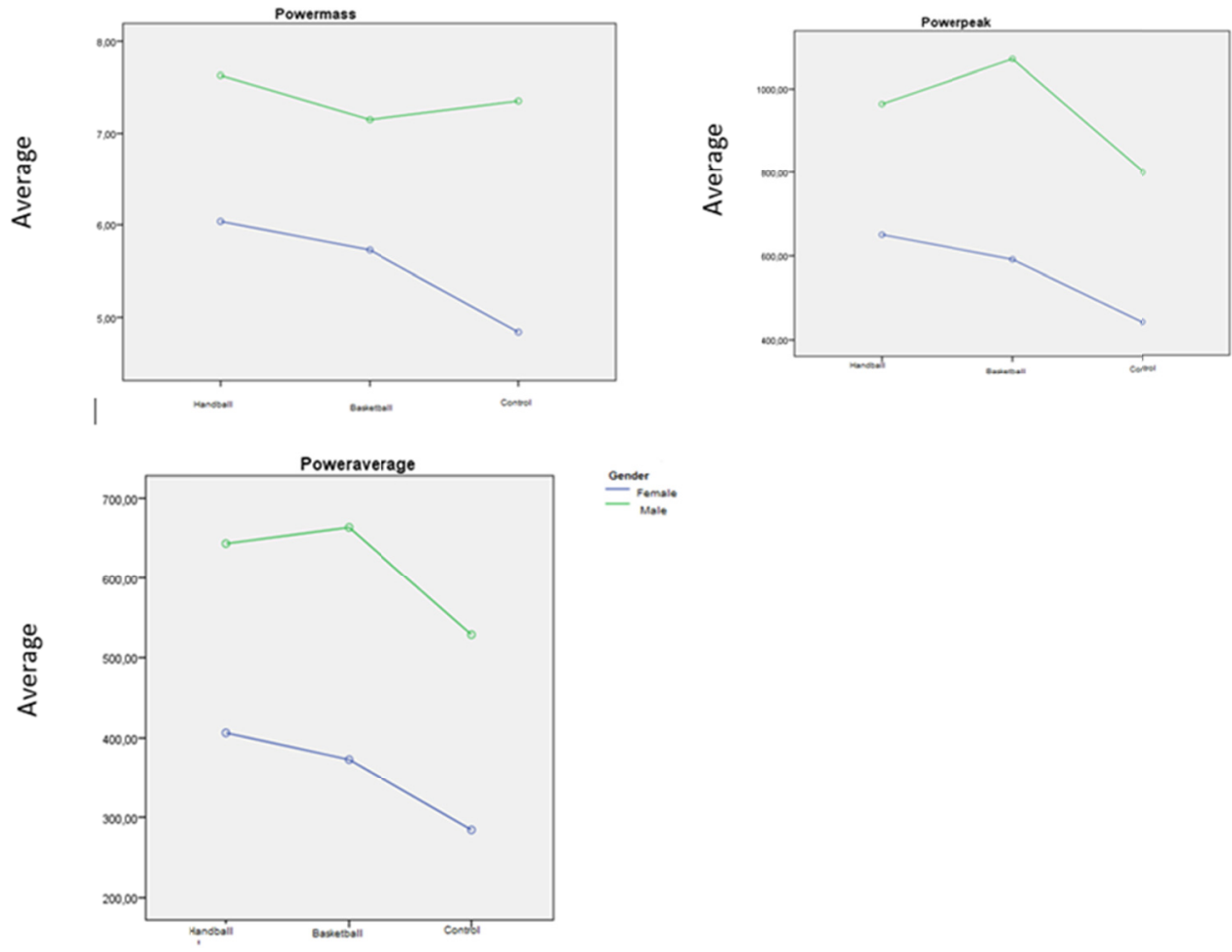

Figure 2. Comparison of Gender* Sports ( Powermass, PowerPeak, Poweraverage)

Above graphics supports MANOVA test. Female participants have lower averages than males do, for three variables. For Powermass value, handball players have higher averages than control group do; for Powerpeak and Power Average variables, control group participants have significantly lower averages than both basketball players and handball players do $(\mathrm{p}<0.05)$.

\section{Discussion and Results}

Anaerobic performance is an important term for short term completed sports and explosive power needed sports branches. Because, the performance of athletes may be affected by individual and environmental elements and may change. Trainers and sports experts first determine the power and capacity of athletes, then prepare a proper training programme for them and can increase their performances (Özkan et al., 2010).

Anaerobic performances of handball and basketball players were analysed by comparing lower and higher extremity values and then those differences were compared with control group results. For high extremity values handball players have significantly higher averages than control group players do ; for lower extremity values control group participants have significantly lower averages than both basketball and handball players do. Handball and basketball players can not create any differences between them. Gacesa et al. (2009) study shows that basketball players have significantly high differences than handball players for some values (Peak Power) in lower extremity. Kalinski et al. (2002) study shows that anaerobic performances of different branches are varied and basketball and handball players have no significant differences between them. Akova et al. (2005) study show that basketball and soccer athletes have significantly higher averages than control group athletes in terms of anaerobic performances.

Analysis showed that there are significant differences on anaerobic performances of participants in terms of gender. Male athletes have significantly higher averages than female athletes in terms of low and high extremity values. Zupan et al. (2009) study of athletes of different branches showed that anaerobic performances of male athletes are significantly higher than female athletes. Thomas and Looney (2009) study of male and female athletes showed that anaerobic performances of male athletes are higher than female athlete performances. Koşar\&İşler (2004) study of university students showed that again performances of male athletes are higher than female athletes. 
This study shows that handball and basketball athletes have significantly higher averages than control group athletes who have no sporting experience in terms of anaerobic performances. Besides, there is no difference between basketball and handball branches. In terms of gender, males have higher performances than females. Gender and branch variables have no joint effect on performances, however, in terms of effect values, gender is the main variable. High extremity values make difference between handball and control group; however they make no difference between basketball and control group. We may say that handball players have more developed high extremity anaerobic performances than basketball players do. Because, handball has more double contacts during the matches. Two branches are similar motoric characteristics and distances, but handball has more contacts with the opponent.

As a result, handball and basketball participants have similar averages in terms of lower extremity values, besides these two branhes have higher averages than control group do. In terms of higher extremity values, only handball players have higher averages than control group do. In terms of gender, males have higher averages than females. There is no joint effect of gender and branch on performances. With future studies, those differences would be made clear and high and low extremity anaerobic performances of several branches could be found out.

\section{References}

Akova, B., Yesilbursa, D., Sekir, U., Gür, H., \& Serdar, A. (2005). Myocardial Performance and Aortic Elastic Properties in Elite Basketball and Soccer Players: Relationship With Aerobic And Anaerobic Capacity. Journal of Sports Science \& Medicine, 4(2), 185.

Bompa, T. O. (2007). Antrenman Kuramı ve Yöntemi "Dönemleme”. Çevirenler: İlknur Keskin, A. Burcu Tuner, Hatice Küçükgöz, Tanju Bağırgan. Spor Yayınevi Ve Kitabevi. Ankara.

Gacesa, J. Z. P., Barak, O. F., \& Grujic, N. G. (2009). Maximal Anaerobic Power Test in Athletes of Different Sport Disciplines. The Journal of Strength \& Conditioning Research, 23(3), 751-755. https://doi.org/10.1519/JSC.0b013e3181a07a9a

Holloszy, J. O., \& Coyle, E. F. (1984). Adaptations of Skeletal Muscle to Endurance Exercise and Their Metabolic Consequences. J. Appl. Physiology, 56(4), 831-938. https://doi.org/10.1152/jappl.1984.56.4.831

Kalinski, M., Norkowski, H., Kerner, M., \& Tkaczuk, W. (2002). Anaerobic Power Characteristics of Elite Athletes in National Level Team-Sport Games. European Journal of Sport Science, 2(3), 1-21. https://doi.org/10.1080/17461390200072303

Koşar, Ş. N., \& Işler, A. K. (2004). Üniversite Öğrencilerinin Wingate Anaerobik Performans Profili ve Cinsiyet Farklılıkları. Spor Bilimleri Dergisi, 15(1), 25-38.

Lidor, R., \& Ziv, G. (2011). Physical And Physiological Attributes of Female Handball Players. Women Sport Physical Act J., 20, 23-38. https://doi.org/10.1123/wspaj.20.1.23

Lidor, R., \& Ziv, G.(2010). Physical And Physiological Attributes of Female Volleyball Players - A Review. J. Strength Cond Res., 7, 1963-1973. https://doi.org/10.1519/JSC.0b013e3181ddf835

Mcardle, W. D., Katch, F. I., \& Katch, V. L. (1996). Exercise Physiology: Energy, Nutrition, and Human Performance. William Sand Wilkins. Baltimore.

Michael, F., Zupan, M. F., Arata, A. W., Dawson, L. H., Wile, A. L., \& Payn, T. L. (2009). Wingate Anaerobic Test Peak Power and Anaerobic Capasity Classifications for Men and Women Intercollegiate Athletes. Journal of Strength and Conditioning Research, 23(9), 2598-2604. https://doi.org/10.1519/JSC.0b013e3181b1b21b

Özkan, A., Koz, M., \& Ersöz, G. (2011). Wingate Anaerobik Güç Testinde Optimal Yükün Belirlenmesi. Spormetre Beden Eğitimi ve Spor Bilimleri Dergisi, 9(1), 1-5. https://doi.org/10.1501/Sporm_0000000192

Pantalis, N., Gal, Z., Ronnie, L., \& Michal, A. (2014). Inter-Individual Variability in Soccer Players of Different Age Groups Playing Different Position. Journal of Human Kinetics, 40, 213-115. https://doi.org/10.2478/hukin-2014-0023

Reza, A. B., \& Rastegar, M. (2012). Correlation Between Running-Based Anaerobik Sprint Test (Rast) Field Tests, Sargent Jump and 300 Yard Shuttle Run Tests With Laboratory Anaerobic Wingate Test in Evaluation Pf indoor Soccer Player's Anaerobic Readiness. Annals of Biological Research, 3(1), 377-384.

Thomas, C., Plowman, S. A., \& Looney, M. A. (2002). Reliability and Validity of The Anaerobic Speed Test and The Field Anaerobic Shuttle Test for Measuring Anaerobic Work Capacity in Soccer Players. 
Measurement in Physical Education and Exercise Science, 6(3), 187-205. https://doi.org/10.1207/S15327841MPEE0603_3

Wilmore, J. H., \& Costil, D. C. (2004). Physiology of Sport and Exercise. Human Kinetics Publisher: Usa.

Wilmore, J. H., \& Costill, D. C. (2004). Physiokg of Sport and Exercise (3rd ed.). Charnpaigr, Il: Human Kinetics.

Ziv, G., \& Lidor, R. (2009). Physical Attributes, Physiological Characteristics, On-Court Performance and Nutritional Strategies of Female and Male Basketball Players. A Riview, Sports Med, 39, 547-568. https://doi.org/10.2165/00007256-200939070-00003

Zupan, M. F., Arata, A. W., Dawson, L. H., Wile, A. L., Payn, T. L., \& Hannon, M. E. (2009). Wingate Anaerobic Test Peak Power and Anaerobic Capacity Classifications for Men and Women Intercollegiate Athletes. The Journal of Strength \& Conditioning Research, 23(9), 2598-2604. https://doi.org/10.1519/JSC.0b013e3181b1b21b

\section{Copyrights}

Copyright for this article is retained by the author, with first publication rights granted to the journal.

This is an open-access article distributed under the terms and conditions of the Creative Commons Attribution license (http://creativecommons.org/licenses/by/4.0/). 